\title{
Laryngoscopy - its past and future
}

Richard M. Cooper BSc MSc MD FRCPC

$M$ AN'S assumption of an upright posture, coupled with our tendency to live in social groups has resulted in some bad habits - simultaneous eating and talking. This has necessitated exclusion of the larynx from the line of sight connecting the mouth to the esophagus. While this does make eating safer and more interesting, it has complicated the task for airway managers.

\section{Past history \\ Early devices}

The early need for laryngeal visualization was surgical. As a medical student, Benjamin Guy Babington created a "glottiscope," in 1829. ' It resembled chopsticks with spatulas on their ends. One shank depressed the tongue while the other was positioned along the palate, reflecting sunlight for illumination and the view of the glottis. It is unclear whether Babington actually saw the glottis, but his device was later termed a laryngoscope by his contemporary, Thomas Hodgkins. Babington was famous for his many contributions to medicine, including the first description of hereditary hemorrhagic telangectasia, but he never published any of his observations in the field of laryngology. ${ }^{2}$

In 1844, John Avery, a surgeon at London's Charing Cross Hospital developed a head-mounted mirror that reflected candlelight onto a mirror housed within a speculum. He didn't report his findings because he wished to first perfect a method of photography. ${ }^{3}$

Manual Garcia (1805-1906), a professor of singing at the Royal Academy of Music in London is generally credited with the discovery of laryngoscopy. In 1854, while strolling in Paris, he saw the sun's image reflected in a store windowpane. He purchased a dental mirror for six francs and used this, in combination with a hand-held mirror reflecting sunlight, to visualize his own larynx and trachea during inspiration and vocalization. He accomplished what those before him were unable to do, largely because of his vocal control and absent gag reflex. His discovery, termed "autolaryngoscopy" (sic!) was presented to the Royal Society in May 1855. Garcia's real interest was to better understand the organ capable of creating such a range of sounds. In 1862 he was granted an honorary medical degree and subsequently invested with many international distinctions. At the age of 100, he was honored by the most prominent laryngologists of his time as the Father of laryngology ${ }^{4}$ and presented with a portrait by John Singer Sargent.

Ludwig Türck, a Viennese neurologist used a technique similar to Garcia's, though apparently unaware of the singing teacher's activities. He used self-made mirrors and performed laryngoscopy on his gagging patients until the autumn sun's diminished intensity forced him to abandon his efforts. Johann Czermak, a physician and physiologist from Budapest, using a table lamp and mirrors borrowed from Türck, performed laryngoscopy. Czermak published and demonstrated his findings widely. He initially acknowledged Türck's contribution, but subsequently withdrew this. What followed was a protracted public debate, referred to as the "Türckish war" about who first used laryngoscopy for diagnostic purposes. ${ }^{3}$ Ultimately, they shared the prize of the Science Academy of France for introducing the laryngoscope into clinical practice. ${ }^{5}$ A laryngology clinic was established in Vienna in 1870 and minor surgical procedures were performed under visual control. In the days prior to local anesthetics, patients had to be trained to suppress their gag reflexes.

Morell Mackenzie learned laryngoscopy from Czermak and went on to found London's first throat hospital, however, the techniques of indirect laryngoscopy were not used to facilitate tracheal intubation. William Macewen, a British surgeon, was the first to

* This resulted in international debate, played out some 40 years later in the journal Laryngoscope. The story of the controversy is itself fascinating.

From the Department of Anesthesia and Pain Management, Toronto General Hospital, University of Toronto, Toronto, Ontario, Canada. Address correspondence to: Dr. Richard M. Cooper, Department of Anesthesia and Pain Management, Toronto General Hospital, 200 Elizabeth St. EN 3-431, Toronto, Ontario M5G 2C4, Canada. Phone: 416-340-5164; Fax: 416-340-3698;

E-mail: richard.cooper@uhn.on.ca

Potential conflict of interest: The author is a consultant and investor in Saturn Biomedical Systems, the manufacturer of a videolaryngoscope. 
intubate the larynx for surgical purposes. He practiced blind, digital intubation on cadavers and eventually employed this technique to perform a composite resection in $1878 .^{6}$ Joseph O'Dwyer, a pediatrician raised in London, Ontario, worked at the Foundling Asylum in New York City, where he developed instruments to enable tracheal intubation which saved the lives of hundreds of children suffocating from diphtheria.

Hans Kuhn modified O'Dwyer's instruments and created a long, flexible metal endotracheal tube and introducer but the technique still depended upon blind insertion, largely because light sources were inadequate to permit progress in direct laryngoscopy (DL). In 1895, Alfred Kirstein learned of an inadvertent tracheal insertion of an esophagoscope, and proceeded to develop a rigid laryngoscope with transmitted light. This consisted of a lamp within the handle, focused on a lens and redirected through the scope by a prism. Chevalier Jackson subsequently modified Kirstein's laryngoscope by providing distal illumination with a tungsten bulb. ${ }^{2}$ In 1913, Henry Janeway devised an open-sided laryngoscope with battery operated distal illumination, specifically for endotracheal intubation.

In 1941, Robert Miller introduced a new, longer, lower profile laryngoscope blade, designed to pick up the epiglottis. This blade required limited mouth opening but also left little space to manipulate the endotracheal tube (ETT), though it differs from the current blade bearing his name. ${ }^{7}$ Two years later, Robert Macintosh described a curved blade, designed to elevate the epiglottis by exerting its force on the base of the tongue. ${ }^{8}$ He believed that reducing contact with the epiglottis would be less stimulating and provide more room for manipulation of the ETT. Although both blades have been variously modified in the interim, they continue to dominate the field of laryngoscopy. Yet they both fail to provide an adequate glottic view in a small but significant number of patients. This resulted in the development of the Siker laryngoscope (1956) with a highly polished surface revealing a mirror image of the glottis, the Huffman prism (1968) which is a clip-on plexiglas device refracting an image $30^{\circ}$ from the line of sight, and the McCoy articulating laryngoscope (1993), all designed to reduce the number of patients with poor views. ${ }^{9,10}$

\section{Positioning for laryngoscopy}

Green, in 1852 advocated the sniffing position because it provided the best pharyngeal illumination when the patient was seated adjacent to a window. Czermak (1858) used this same position for indirect mirror laryngoscopy and Kirstein, 30 years later used it for DL. ${ }^{11}$ It was Chevalier Jackson who used the sniffing posture in the recumbent patient (1913), elevating the head and extending the neck while using his left hand to hold the laryngoscope and his right hand to perform surgery. Killian devised a suspension laryngoscope, which freed up the operator's hands to perform surgery, however, it placed the patient in a position of extensionextension. Brunings recognized that this reduced anterior laryngeal exposure and added a device which applied external laryngeal pressure. ${ }^{11}$

In 1944, Bannister and MacBeth compared a variety of head and neck positions using lateral radiographs and concluded that cervical flexion and atlanto-axial extension provided the best alignment of the mouth, pharyngeal and laryngeal axes. ${ }^{12}$ Adnet questioned whether their findings supported their conclusions $^{13}$ and set about to re-examine this issue. Using magnetic resonance imaging, his group concluded that the sniffing position does not align the three axes in awake, conscious volunteers with normal anatomy ${ }^{14}$ nor does it provide better glottic exposure than simple extension except in patients with morbid obesity and reduced cervical mobility. ${ }^{15}$ Hochman et al. prospectively investigated 20 patients undergoing (diagnostic) DL, comparing three positions: cervical extension-atlantoaxial extension, extension-flexion (sniffing) and flexion-flexion. ${ }^{11}$ Interestingly, they found that in patients "predisposed to difficulty", flexion-flexion actually provided the best view. And so, 152 years after the recommendation of the sniffing position, long after we've forgotten why this position was advocated, it remains unclear what position affords the best view. But it is clear that positioning alone does not align the airway axes and we must apply force to achieve this.

\section{Where are we now and where are we going? What's wrong with $D L$ ?}

Rose and Cohen looked at airway problems in over 18,500 adult non-obstetrical patients. DL was the first choice $98 \%$ of the time. Among these patients, the failure rate was $0.3 \%$ and "awkward" or "difficult" in $2.5 \%$ and $1.8 \%$ respectively. More than three laryngoscopies were required in $0.4 \%$ of patients in whom DL was chosen. ${ }^{16}$ Adnet and co-workers recognized that difficulties involving laryngoscopy and intubation are poorly described and proposed an intubation difficulty score. No difficulties were encountered in $55 \%$ of 1,171 adult patients; minor intubations difficulties were encountered in 37\%; two or three laryngoscopies were required in $9 \%$ of cases and more than three attempts were required $3 \%$ of the time. ${ }^{17}$ However, even "non-difficult" endotracheal intubation may be associated with airway injury. The ASA closed claims analysis involving 
266 incidents of airway injury found that $80 \%$ of laryngeal injuries occurred when laryngoscopy and intubation was thought to have been easy. ${ }^{18}$

The inability to see the larynx generally results in multiple or prolonged laryngoscopic attempts with increasing force, and is associated with esophageal, pharyngeal and dental injury, ${ }^{18}$ arterial desaturation, hemodynamic instability and unplanned intensive care unit admissions. ${ }^{16}$ Poor laryngeal exposure (CormackLehane grade III or IV) occurs in 1.5 to $8.5 \%$ of adult laryngoscopies. ${ }^{19}$ But poor laryngeal exposure may still be associated with successful intubation. An American Society of Anesthesiologists Task Force's definition of a difficult laryngoscopy states that "it is not possible to visualize any part of the vocal cords after multiple attempts" and a difficult tracheal intubation as one which "requires multiple attempts." 20 Though successfully accomplishing intubation is important, it is not enough. Intubation in the absence of an adequate laryngeal view should be regarded as a "near-miss." This will provide the necessary incentives to improve airway management techniques and reduce our reliance upon luck and multiple or forceful laryngoscopies. While blind techniques such as gum elastic bougies, may be acceptable in a rescue setting, they should not be encouraged as proposed by Cormack and Lehane. ${ }^{21}$

Minor airway injury has been attributed to endotracheal intubation per se. Tanaka et al. demonstrated laryngeal edema and an increase in airway resistance in patients who had been managed by ETT compared with those managed by laryngeal mask airway. ${ }^{22}$ The variety of supraglottic airways and their popularity, particularly the laryngeal mask airway, may circumvent injuries resulting from laryngoscopy and tracheal intubation and complications from neuromuscular blockers, though they may create problems of their own.

The flexible fibreoptic bronchoscope (FOB) is undeniably a useful tool and facility with it is an essential skill for airway managers. The device is versatile, sophisticated, expensive, fragile and reliable in experienced hands. It does however, require a completely different skill-set from DL, though this can (and should) be acquired in a controlled, structured environment. ${ }^{23}$ Fibreoptic intubation (FOI) also requires expert assistance and may take some time which can be problematic in an anesthetized, apneic patient at risk of arterial desaturation or aspiration. Consequently, in the anticipated difficult airway, FOI is often advocated in the awake or sedated state. Adequate topical anesthesia contributes to the success of the procedure, however secretions may reduce mucosal contact and obscure the view. Fogging of the image may also present a problem. A more fundamental concern with FOI is that the endoscope is used to locate the larynx and enter the trachea. Once there, it serves as a simple stylet over which an ETT is advanced. Not uncommonly, tube advancement through the larynx is more stimulating and a greater challenge than insertion of the FOB. FOI remains a "blind technique" and may result in airway injury. ${ }^{24}$

Fibreoptic technology has also been adapted for rigid laryngoscopes, anatomically shaped and designed specifically for intubation. Examples of these devices are the Bullard laryngoscope (BL; ACMI Circon, Santa Barbara, CA, USA), the WuScope (Achi Corporation, Freemont, CA, USA) and the Upsherscope Ultra (Mercury Medical, Clearwater, FL, USA). Rigidity contributes to their simplicity and provides protection for the delicate fibreoptic bundles. The Bullard scope requires an interincisor gap of only 6- $\mathrm{mm}$, and all these devices are capable of providing far better laryngeal exposure than can be achieved by DL. The BL has been the most extensively studied though most of the published reports are small, uncontrolled series. One early study found that a poor glottic view obtained by DL was not predictive of the time required or ultimate success using the $\mathrm{BL} .{ }^{25} \mathrm{~A}$ recent comparison of the BL with FOI was conducted in patients with cervical immobilization. Each of 50 patients was intubated with both devices, half with cricoid pressure $(\mathrm{CP})$. All patients were successfully intubated with both devices but BL required less time and $\mathrm{CP}$ interfered less with success. ${ }^{26}$ The WuScope was studied in 69 patients by relatively inexperienced operators. Despite anatomic features generally associated with difficult laryngoscopies in 24 of these patients, most were intubated with little difficulty. ${ }^{27}$ When Macintosh laryngoscopy and the WuScope were compared in patients with manual in-line cervical immobilization, significantly better views resulted with the WuScope with comparable first attempt successes. $^{28}$ The original Upsherscope had a simple design but most users experienced disappointing results. It has recently been re-incarnated as the UpsherScope Ultra incorporating a number of refinements, the most import being a better ETT delivery system. ${ }^{29}$ All three of these devices can be attached to a video-display; they generally result in superior glottic exposure, even in situations that are challenging and all require practice in normal airways to achieve proficiency. Surveys in Canada ${ }^{30}$ and the United States $^{31}$ have shown that few anesthesiologists have made this investment.

More recently, compact, robust, high-resolution videochips have become available which can be 
embedded within laryngoscopes. These devices can resemble conventional laryngoscopes ${ }^{32,33}$ or be modified to provide an alternative laryngeal view. ${ }^{34}$ Why consider the use of these new devices? Firstly, they permit simultaneous viewing by mentor and supervisor and may accelerate the instruction of laryngoscopy. Secondly, these images can be captured and replayed for analysis. The video or static images may be useful for research, teaching or clinical documentation. Thirdly, they may enable visualization in settings that would otherwise be challenging ${ }^{35, \mathrm{~A}}$ or not possible. ${ }^{34}$ Fourthly, since tissues do not have to be compressed and distracted to achieve a line-of-sight, there may be less stress and trauma to the patient during laryngoscopy. Fifthly, positioning should not impact upon the laryngeal view. Finally, the operation of these new airway devices so closely resembles the conventional laryngoscope that the barriers associated with flexible and rigid FOI may not exist. They may, however demand a new dexterity to direct the ETT through a well-seen glottis. Difficult laryngoscopy is a term that had previously applied to problems with line-of-sight techniques. If new technologies enable us to look around corners and airway managers become confident of their ability to consistently view the larynx though this contention remains to be confirmed - our attention can re-focus on our ability to maintain adequate oxygenation and protection from aspiration.

The laryngoscope of the future will provide predictable laryngeal exposure and consistently successful intubation. It will be easy to learn, quickly performed and will impose less stress upon the patient. It will be inexpensive to acquire and robust enough to withstand the hostile environment of the operating room. It will enable us to look around corners, rather than compelling us to straighten them. Although sunlight is nice, we will not be dependent upon it for adequate laryngeal illumination.

A Cooper RM, Pacey JA, Bishop MJ, McCluskey SA. Early clinical experience with a new videolaryngoscope (GlideScope). 2004 (submitted).

\section{References}

1 Bailey B. Laryngoscopy and laryngoscopes--who's first?: the forefathers/four fathers of laryngology. Laryngoscope 1996; 106: 939-43.

2 Koltai PJ, Nixon RE. The story of the laryngoscope. Ear Nose Throat J 1989; 68: 494-502.

3 Alberti PW. The history of laryngology: a centennial celebration. Otolaryngol Head Neck Surg 1996; 114: 345-54.

4 Bailey BJ. What's all the fuss about? The laryngoscope pages causes an international incident. Laryngoscope 1996; 106: 925-7.

5 Weir N. Otolaryngology: An Illustrated History. London: Butterworth \& Co. Ltd.; 1990.

6 Macewen $W$. Introduction of tracheal tubes by the mouth instead of performing tracheotomy or laryngotomy. Br Med J 1880; II: 122-4.

7 Miller RA. A new laryngoscope. Anesthesiology 1941; 2: 317-20.

8 Macintosh RR. Ralph M. Waters Memorial Lecture. Anaesthesia 1970; 25: 4-13.

9 Jephcott A. The Macintosh laryngoscope. A historical note on its clinical and commercial development. Anaesthesia 1984; 39: 474-9.

10 Zadrobilek E, Regal $W$. The Macintosh laryngoscope: sixtieth anniversary of the first published description. Internet Journal of Airway Management 2003; 2.

11 Hochman II, Zeitels SM, Heaton JT. Analysis of the forces and position required for direct laryngoscopic exposure of the anterior vocal folds. Ann Otol Rhinol Laryngol 1999; 108: 715-24.

12 Bannister FB, MacBeth RB. Direct layrngoscopy and tracheal intubation. Lancet 1944; 651-4.

13 Adnet F, Borron SW, Lapostolle F, Lapandry C. The three axis alignment theory and the "sniffing position": perpetuation of an anatomic myth? Anesthesiology 1999; 91: 1964-5.

14 Adnet F, Borron SW, Dumas JL, Lapostolle F, Cupa M, Lapandry C. Study of the "sniffing position" by magnetic resonance imaging. Anesthesiology 2001; 94: 836-41.

15 Adnet F, Baillard C, Borron SW, et al. Randomized study comparing the "sniffing position" with simple head extension for laryngoscopic view in elective surgery patients. Anesthesiology 2001; 95: 836-41.

16 Rose DK, Cohen MM. The airway: problems and predictions in 18,500 patients. Can J Anaesth 1994; 41: 372-83.

17 Adnet F, Racine SX, Borron SW, et al. A survey of tracheal intubation difficulty in the operating room: a prospective observational study. Acta Anaesthesiol Scand 2001; 45: 327-32.

18 Domino KB, Posner KL, Caplan RA, Cheney FW. 
Airway injury during anesthesia: a closed claims analysis. Anesthesiology 1999; 91: 1703-11.

19 Crosby ET, Cooper RM, Douglas MJ, et al. The unanticipated difficult airway with recommendations for management. Can J Anaesth 1998; 45: 757-76.

20 Practice Guidelines for Management of the Difficult Airway. An updated report by the American Society of Anesthesiologists Task Force on Management of the Difficult Airway. Anesthesiology 2003; 98: 1269-77.

21 Cormack $R S$, Lehane J. Difficult tracheal intubation in obstetrics. Anaesthesia 1984; 39: 1105.

22 Tanaka A, Isono S, Ishikawa T, Sato J, Nishino T. Laryngeal resistance before and after minor surgery: endotracheal tube versus laryngeal mask airway. Anesthesiology 2003; 99: 252-8.

23 Naik VN, Matsumoto ED, Houston PL, et al. Fiberoptic orotracheal intubation on anesthetized patients: do manipulation skills learned on a simple model transfer into the operating room? Anesthesiology 2001; 95: 343-8.

24 Maktabi MA, Hoffman H, Funk G, From RP. Laryngeal trauma during awake fiberoptic intubation. Anesth Analg 2002; 95: 1112-4.

25 Cooper SD, Benumof JL, Ozaki GT. Evaluation of the Bullard laryngoscope using the new intubating stylet: comparison with conventional laryngoscopy. Anesth Analg 1994; 79: 965-70.

26 Shulman GB, Connelly NR. A comparison of the Bullard laryngoscope versus the flexible fiberoptic bronchoscope during intubation in patients afforded inline stabilization. J Clin Anesth 2001; 13: 182-5.

27 Smith CE, Sidhu TS, Lever J, Pinchak AB. The complexity of tracheal intubation using rigid fiberoptic laryngoscopy (WuScope). Anesth Analg 1999; 89: 236-9.

28 Smith CE, Pinchak AB, Sidhu TS, Radesic BP, Pinchak $A C$, Hagen JF. Evaluation of tracheal intubation difficulty in patients with cervical spine immobilization: fiberoptic (WuScope) versus conventional laryngoscopy. Anesthesiology 1999; 91: 1253-9.

29 Hagberg $C A$. Special devices and techniques. Anesthesiol Clin North America 2002; 20: 907-32.

30 Jenkins K, Wong DT, Correa R. Management choices for the difficult airway by anesthesiologists in Canada. Can J Anesth 2002; 49: 850-6.

31 Rosenblatt WH, Wagner PJ, Ovassapian A, Kain ZN. Practice patterns in managing the difficult airway by anesthesiologists in the United States. Anesth Analg 1998; 87: 153-7.

32 Kaplan MB, Ward DS, Berci G. A new video laryngoscope--an aid to intubation and teaching. J Clin Anesth 2002; 14: 620-6.

33 Weiss M, Schwarz U, Dillier CM, Gerber AC. Teaching and supervising tracheal intubation in paediatric patients using videolaryngoscopy. Paediatr Anaesth 2001; 11: 343-8.

34 Cooper RM. Use of a new videolaryngoscope (GlideScope $($ ) in the management of a difficult airway. Can J Anesth 2003; 50: 611-3.

35 Agro F, Barzoi G, Montecchia F. Tracheal intubation using a Macintosh laryngoscope or a GlideScope ${ }^{\circledR}$ in 15 patients with cervical spine immobilization. $\mathrm{Br} \mathrm{J}$ Anaesth 2003; 90: 705. 